\title{
What Anti-realism About Hinges Could Possibly Be
}

Annalisa Coliva $1 \square$

Email a.coliva@uci.edu

1 Department of Philosophy, University of California, Irvine, Irvine, CA, USA

\section{Abstract}

The abstract is published online only. If you did not include a short abstract for the online version when you submitted the manuscript, the first paragraph or the first 10 lines of the chapter will be displayed here. If possible, please provide us with an informative abstract.

The paper addresses the issue of what epistemic anti-realism could possibly be- It argues that it can take the form of a in the context of "hinge epistemology." That is to say, of an account of According to this new epistemological trend, justification, which eneeives of warrant as dependsent on evidence together with general background assumptions - for example, that there is an external world, that our sense organs are mostly reliable, that we are not the victims of persistent and lucid dreams hat has regularly happened in the past will happen in the futtre, that people are generally reliable informants, and so on. The paper then addresses two issues. First, whether these assumptions are arbitrary, as relativists would claim. Second, how we should conceive of their metaphysical status. It responds negatively to the first question and puts forward an anti-realist conception of hinges to respond to the latter. Central to the proposal is that the kind of truth that can be predicated of hinges is of a minimalist kind. The paper also explores the compatibility of minimalism about hinges' truth and alethic pluralism .

\section{Introduction}

In a number of writings, I have been developing a form of hinge epistemology inspired by Wittgenstein's remarks in On Certainty (1969). The key take-home message is that justification and knowledge-to the extent that knowledge is thought of as, roughly, justified true belief-always take place within a system of assumptions. For instance, for Wittgenstein, it is only by taking for granted that the Earth has existed for a long time that we can consider fossils as bearing on the determination of the specific age of the Earth. If we doubted that the Earth had existed for a long time, we could no longer consider fossils as being evidentially significant for that specific inquiry, since we could no longer take for granted that their formation took place on the Earth throughout a long amount of time. Their presence would then be compatible with alternative hypotheses such that the Earth was created just a little while ago, replete with all the fossils we have found on it, which were created on some other planet or in some sci-fi lab, for instance. Wittgenstein called "hinges" propositions like "The Earth has existed for a very long time," and thought of them as conditions of evidential significance - that is, as what needs to stay put for the justification of specific empirical propositions to be possible at all. He also had a very wide conception of hinges. In his view, they ranged from very general ones like "The Earth has existed for a very long time," to more specific ones like "Nobody has ever been on the Moon"; from impersonal ones, like the previous ones, to personal ones, like "This is my hand" and "My name is AC"; and also from universal ones, like "Cats don't grow on trees," to only contextual ones, like "Here is my hand." Furthermore, he thought of them as playing a rule-like role not just with respect to the conditions of evidential significance but also of meaningful discourse, including meaningful doubt. Thus, for instance, if one really doubted that there is a hand here (while holding up one's hand in front of one's nose), then it would no longer be clear what one would mean by "hand." Hinges thus became Wittgenstein's ammunition in stock against various forms of scepticism. On the one hand, by relying on their meaning-constitutive role, they were used against Cartesian scepticism to claim-well before Putnam's brains in a vat - that if we were dreaming we would also be dreaming that our words have a meaning. So we could not meaningfully entertain the hypothesis that we were dreaming (or that we were brains in a vat, or that we were living in the Matrix, or that we were being deceived by an evil demon) after all. On the other hand, by relying on their role of conditions of evidential significance, they were used against forms of Humean scepticism, to claim that for doubts to get any purchase at all, hinges had to stay 
put. In particular, that real, empirical and specific doubts could only be raised by taking for granted the existence of physical objects, and the broad well-functioning of our perceptual and cognitive faculties. Thus, to conclude that "There is an external world," "My senses are broadly well-functioning" or "My cognitive faculties are broadly reliable" are not rationally held because they cannot be empirically justified would depend on failing to realise that these propositions themselves contribute to the very possibility of there being empirically justified beliefs and doubts at all. To doubt of them would thus be self-defeating, as it would make doubt ultimately impossible. ${ }^{1}$

In my systematic - as opposed to historical — work on hinge epistemology, I have proposed a different view of hinges, while retaining the gist of what I consider Wittgenstein's main insight in On Certainty. First, I have restricted my attention to what Dretske used to call "heavy-weight assumptions." That is, very general propositions like "There is an external world," "Our sense organs are broadly well-functioning," "Our cognitive faculties are broadly reliable." 2 Thus, I have restricted the scope of hinges to those that are constitutive of basic epistemic practices or methods of inquiry, broadly conceived. For one could not even start investigating a mind-independent physical reality if one did not take for granted that there are physical objects, that one's sense organs by and large correctly represent them, and that one's cognitive faculties allow one to form generally correct beliefs about them. Moreover, I have not made any play with the idea that these heavy-weight assumptions could be less than propositional in nature, like rules are generally thought of as being. ${ }^{3}$ Finally, I have not considered hinges as meaning-constitutive rules, mainly because it does not seem impossible to think of cases in which one has acquired the meaning of the relevant words by being in contact with their referents, thus being able to ostensively define their meanings and make correct applications of those terms, and then be placed, unbeknownst to one, in a sceptical scenario radically disconnected from the external world, while still retaining - at least for the time being - the initial meanings and concepts. In such a scenario, asking oneself whether one is dreaming, or whether one is brain-envatted, or whether one is living in the Matrix, et cetera, would not seem immediately to entail a violation of the rules of semantic significance. Thus, however short-lived that radical sceptical doubt could be, it would not be altogether unintelligible. Furthermore, it is advisable not to make one's anti-sceptical strategy hostage to the success of this or that theory of meaning. Hence, I haven't pursued any semantic anti-sceptical strategy centered on the role of hinges as meaning-constitutive rules.

Retaining the propositionality of hinges and making them the content of a propositional attitude of acceptance brings with it several problems, however. ${ }^{4}$ One might think that it would re-open the door to Cartesian scepticism, since it would no longer allow one to claim that imagining radically sceptical scenarios would ultimately be self-defeating as this would entail a violation of the conditions for meaningful discourse. This, however, is not the main problem, in my view. For one could still make other moves to counter that form of scepticism. In particular, by denying the unconditional validity of Closure, one could defend the idea that we know that there is a hand here, even if we do not know that there is an external world, or that we are not dreaming, or that we are not brains in a vat, et cetera. One could then defend that position from the charge of condoning abominable conjunctions by noticing that, ${ }^{5}$ though not an instance of knowledge or of justified belief, there being an external world, not dreaming, or not being a brain in a vat are rational assumptions we are entitled to make insofar as they are constitutive of epistemic rationality. Of course, one may object to the extended rationality view I proposed, according to which epistemic rationality extends beyond those empirical beliefs that are epistemically justified to the very conditions of possibility of that kind of justification. This is not the place to rehearse possible criticisms and to respond to them. ${ }^{6}$ Rather, in my view, the more serious issue, and a very intricate philosophical question indeed, is to understand the metaphysical status of hinges. One way of presenting that challenge is by phrasing it semantically, as hinging - pun intended - on the kind of truth hinges are supposed to enjoy. That is to say, when we say " There is an external world' is true," what kind of truth are we attributing to the proposition expressed by the sentence "There is an external world"? Is it robustly correspondentist, or evidence-dependent, or, finally, minimalist? This is the topic of the present paper. As is apparent, it is a theme at the interface between epistemology and metaphysics, with the potential of re-shaping reflection in each of these areas - particularly in epistemology. For commitment to realism seems to be a tenet of the discipline. That is, it is usually taken for granted that there are physical objects - understood, in a Humean fashion, as objects existing continuously even when not perceived, and as not dependent for their existence on anyone's minds. What epistemology then pursues is either an explanation of how we can form justified or even knowledgeable beliefs about such mindindependent entities, once we start out with the Quinean "meager input" of experience (Quine 2008, 297); or else, an understanding of how we may claim that we are within our epistemic rights in having those beliefs, 
vis-à-vis various kinds of sceptical paradoxes. The former is the project pursued by naturalised epistemologies, the latter the one pursued by normative ones. Quine too, however, was well aware that the two projects were not in opposition to one another, but rather complementary. For he recognised that what is the tenet of naturalized epistemology is in fact what normative epistemology tries rationally to redeem.

As a methodological point, in the following I will be exploring the issue of the metaphysical status of hinges not only by performing a semantic ascent, but also by bringing in considerations that fall within the normative project in epistemology. For what is worth, let me just record here, with no space to argue for it in any detail, that, in a spirit of division of cognitive labour, I consider the naturalised project more of a project for cognitive sciences nowadays, rather than for philosophy. Thus, it will be left aside in the following.

\section{Realism About Hinges: A Correspondentist Conception of Hinges' Truth?}

The traditional realist view has it that a sentence $\mathrm{S}$, expressing a proposition $p$, is true iff it is the case that $p$ (or it is a fact that $p$ ). Thus, $\mathrm{S}$ is true iff $p$ is a state of affairs that obtains and whose obtaining is prior and independent of its being the object of a representation (linguistic or otherwise). Accordingly, the English sentence "There is an external world" would express the proposition that there is an external world and it would be true iff there were such an external world. That is, if its existence were prior and independent of our thinking or talking about it. It is because there is such a mind-independent world, then, that if we say (or think) "There is an external world" what we say (or think) is true. What we would thereby say (or think) would be true because it would correspond to how things are in the world, independently of us. The world is what it is, it is structured the way it is, and when we talk (or think) about it, what we say (or think) is true just in case it mirrors or reflects that outer entity. In the usual terms of the Euthyphro contrast (cf. Wright 1992, 108-39), for a realist it is because there is an external world that, when we say (or think) there is, what we say (or think) is true; not the other way around. That is, it is not because we hold it true that there is an external world that it is the case that there is.

Now, as remarked at the end of the previous section, in epistemology the realist side of the Euthypro contrast is usually taken for granted. The question then is how we can ascertain or claim that we are within our epistemic rights in taking it for granted that there is an external world. The problem of philosophical scepticism, in my view, just dramatises this issue. If it takes the form of a Cartesian paradox, it challenges us by claiming that if we were dreaming (or were in any of the other Cartesian scenarios that posit a broad disengagement from reality) we would have no evidence we could legitimately appeal to, to reassure ourselves that there is indeed a world of mind-independent physical entities. For that evidence would be compatible with its being dreamt of (or otherwise produced in abnormal ways). ${ }^{8}$

If it took the form of a Humean paradox, in contrast, scepticism would challenge us by considering that in order to be able to justifiably hold any of our ordinary empirical beliefs concerning specific mindindependent physical objects, based on our perceptual experiences, we should already take it for granted that there is an external world, which is broadly manifested to us through our sense organs. Thus, we cannot obtain a justification to believe in the existence of the external world by running anything like a Moorean argument, as that kind of argument would be question-begging. 9

Now, it would take us too far afield to rehearse the long history of the attempts to meet these challenges, even if we were to confine ourselves to just its most relevant episodes in contemporary philosophy (for an overview see Coliva 2012). We have quickly seen how a semantic strategy could try to respond to Cartesian scepticism and the reasons why it does not seem ultimately satisfactory. Serious concerns can be raised for contextualist strategies too (see for instance DeRose 1995) which, at any rate, are designed to allow for the legitimacy of sceptical doubts, albeit only in philosophical contexts. Strategies inspired by Robert Nozick's (1981) and Fred Dretske's (1970) work on conditional analyses of knowledge would then make play with counterfactual considerations regarding knowledge (if not justification). While they are considered by several philosophers to be problematic as analyses of knowledge as such, when assessed with respect to their anti-sceptical potential, they would all seem to suffer from the same kind of very general problem. Namely, let us concede that the possible world where there are physical objects and we perceptually interact with them and the ones where a Cartesian sceptical scenario obtains are far apart. Yet, the question remains as to 
how we can tell which one, among these possible worlds, is the actual one. Positing that it is the former rather than the latter is philosophically impotent vis-à-vis the Cartesian sceptical challenge. By those lights, that is just a mere posit, which reveals our prejudice, preferences, or habits - at any rate, nothing for which we could provide any kind of epistemic justification.

In the remainder of this section, let me just say a few words against two prominent strategies meant to counter the Humean sceptical paradox. The first is Jim Pryor's $(2000,2004)$, which relies on a liberal (or dogmatic) understanding of the structure of empirical justification, whereby just by having a hand-like experience, absent defeaters, one would thereby possess a justification for "Here is a hand," which would then transmit to the conclusion of a Moorean-argument, namely "There is an external world." Among the various problems that beset this strategy (for criticisms see Coliva 2015, 20-28, 58-64), the one which immediately meets the eye is that if we conceive of experiences in an internalist fashion, as Pryor does, there seems to be nothing in the experience itself to make it more likely that we are indeed seeing a hand, rather than having an impression as of a hand, while being ourselves brains in a vat, say (cf. White 2006 and Wright 2007). If so, then, the strategy does not meet the Humean sceptical challenge. For it does not have the resources to claim that it is indeed the case that our experiences as such, absent defeaters, and unaided by collateral assumptions regarding their provenance, give us a justification to believe that there is a hand here. Absent such an immediate justification, then, the strategy does not have the resources to rehabilitate the epistemic legitimacy of a Moorean anti-sceptical argument.

One might then think that the problem with the liberal counter is not so much the structure of epistemic justification it proposes, as the conception of perceptual experience it relies on. Disjunctivist strategies, proposed by John McDowell (1982, 1995) and, more recently, by Duncan Pritchard (2016), can be seen as capitalising on this intuition. Accordingly, if we are perceiving a hand, then there is a hand there and we have a justification to believe there is (or even have knowledge of that). If there is no hand, then we are not perceiving in the first place. Yet, there is no highest common factor between perceiving a hand or merely hallucinating, or seeming to see one. If we are in the favourable disjunct, we then possess an immediate justification for (or even knowledge of) "Here is a hand," which transmits to the conclusion of the Moorean argument. Thus, we have a direct reply to the Humean sceptical challenge.

As simple and pleasing as this strategy may be, two immediate worries arise, however. First, it is hostage to a conception of perception that is not sacrosanct, and indeed that is challenged by contemporary work on the psychology of perception. ${ }^{10}$ Now, it is true that, methodologically, I think philosophy and psychology should each take care of themselves. Yet, I would be very worried if a philosophical theory about one or the other of our cognitive faculties were not compatible with our best science about that very faculty. True, science may evolve and compatibility between it and a given philosophical view be re-established, but if it doesn't (or if it hasn't yet) we can't simply dismiss its findings with a shrug of the shoulders. Prudence would thus recommend suspending judgement and looking for alternative philosophical strategies. Second, one may happily agree that if we perceive a hand, then we have an immediate justification for (or knowledge of) "Here is a hand" (which could then transmit to "There is an external world" via the Moorean argument). Yet that is just a conditional claim, and the question remains as to how to discharge its antecedent. In particular, how can we tell if we are right now perceiving, as opposed to merely having an experience as of a hand (see Wright 2002)?

Finally, let us acknowledge the interdependence of these very sceptical paradoxes and the realist conception of hinges such as "There is an external world." A moment's reflection suffices to see that the Cartesian paradox trades on the distance, posited by realism, between the mind and the world. The world is what it is, independently of our minds, and if so, why be so arrogant to think that it should be accessible to us or that it should be accessible to us just as is? Whence the play with all those scenarios which are supposed to save appearances (literally), while making salient to us the discomforting possibility that things (in themselvesone would be tempted to say), are rather different, thus leaving us with the impossibility of ascertaining whether they are one way or the other.?

Now, true, the Humean paradox does not make play with far-fetched sceptical scenarios. Yet it tells us that all empirical justification and knowledge take place within a system of assumptions - paramount among them "There is an external world"-for which we cannot have independent justification (or which we cannot have independent knowledge of). Yet it is precisely such independence that would make them justified, if we 
could somehow bridge the gap. Conversely, it is because such independence is built into the problem that it becomes impossible to redeem our justification for those very assumptions. For, recall, we are looking for an epistemic justification for "There is an external world." That is, for a justification which allows us to believe that that is the case (or that it is more likely the case) and therefore that allows us to claim that our representation of the world as populated by mind-independent objects is true because that is exactly how the world is. Yet, if that justification is supposed to come from the senses, hence from our minds, how could it in and of itself certify that it is in keeping with a mind-independent reality?

In short, both forms of sceptical paradox make play with the supposed gap between, and independence of mind and world and display the difficulty of reconquering the world, once that distance is taken as given.

\section{Anti-realism About Hinges I: An Evidence-Dependent Conception of Hinges' Truth?}

One might then be tempted to embrace the opposite, anti-realist side of the Euthyphro contrast and construe it, as has been the case for comic and taste discourse, as grounded in our human reactions (see Wright 1992 for this strategy). For example, "This joke is funny" would not be true because the proposition expressed by that sentence corresponds to a mind-independent reality that already carves up the world into jokes that are funny and jokes that are not. Rather, it is true because - given our own reactions - we judge that that joke is funny, while other ones are not. Similarly, on this account, "There is an external world" would not be true because it corresponds to a mind independent reality. Rather, it would be true because, based on our evidence, we judge that that is the case. That is, it looks to us as if there are objects that persist even when they are not perceived by us, or that seem to afford coherent perceptions over time and across various sensory modalities. We therefore have reasons to believe that they exist independently of us.

The problem with this strategy, however, is that it is supposed to ground the truth of "There is an external world" in our own evidence in favor of it. Yet, that evidence would be sensory evidence. Now, as we just saw in connection with Cartesian and Humean scepticism, on the one hand, that evidence would be compatible with its being produced in abnormal ways, which do not depend on any causal interaction with physical objects. On the other, we have already pointed out how, in the vein of Humean scepticism, its role as evidence which justifies us in believing that there is a hand, where we seem to see it, for instance, owes to the collateral assumption that it be produced in what we take to be the normal way. That is, through causal, sensory interaction with a world populated by mind-independent physical objects. Thus, the problem facing a supporter of the anti-realist side of the Euthyphro contrast is that the evidence we have cannot justify, in and of itself, the belief in the existence of an external world. Investigating the disanalogy between comic discourse and discourse about the very existence of an external world will prove instructive. So let me address it in the remainder of this section.

With comic discourse, it is readily admissible that we are somehow recording our own subjective reactions to jokes, for instance. Thus, the provenance of truth, when we ascribe it to the proposition expressed by "This joke is funny," can easily be considered to be from our own minds. With "There is an external world," however, there is no such readily available sense according to which we would thereby be recording our own subjective reactions - unless one wished to go idealist, or phenomenalist. Yet, as long as one takes "There is an external world" at face value, as affirming the existence of mind-independent physical objects, the prospects of an evidence-dependent account of its truth look dim.

To put it in terms familiar from the debate on alethic pluralism (see for instance, besides Wright 1992, also Lynch 2009 and Pedersen and Wright 2013), alethic anti-realism, cashed out in an evidence-dependent way as amounting to truth understood, for instance, as superassertability (see Wright 1992), has traditionally been proposed for those areas of discourse for which it is a priori that all true propositions are in principle knowable (or at least justifiable). Yet, it is the very gist of the two forms of sceptical paradox we have been considering that "There is an external world" does not fall in that remit.

If these were the only options, we would then face a serious situation. As a result of the sceptical paradoxes, we could not know (or justifiably believe) that there is an external world; nor, it seems, could we make sense of the idea that that is a proposition capable of being true, at least in principle. 
I surmise that something like finding himself in this bind led Wittgenstein to propose (if not to fully endorse) the view that hinges are neither known, nor unknown, justified or unjustified, and are actually neither true nor false $(1969, \S 94,205)$. Connectedly, it was (possibly) finding himself in such a conundrum that led him to hold that their role had to be akin to that of rules. That is, rather than be descriptive, their role would be prescriptive - similar to " $p$ !" (where $p$, in this case, would be the proposition that there is an external world and the action commended the one of accepting that $p$ and of behaving in accordance with what $p$ entails).

\section{Anti-realism About Hinges II: A Minimalist Conception of Hinges' Truth}

Still, Wittgenstein himself in On Certainty toys with a different idea regarding hinges' truth. Namely, that:

(1) Their truth "belongs to our frame of reference." $(1969, \S 83)$ That is, that we regard them "as certainly true also characterizes [our] interpretation of experience.” $(1969, \S 145)$

(2) The truth of our statements is the test of our understanding of these statements $(1969, \S 80)$. "That is to say: if I make certain false statements, it becomes uncertain whether I understand them.” $(1969, \S 81)$

(3) If one thought that "if everything speaks for an hypothesis and nothing against it" it certainly "agrees with reality [that is, with mind-independent] facts", one would already be "going round in a circle." (1969, §191) Again, "the reason why the use of the expression 'true or false' has something misleading about it is that it is like saying 'it tallies with the facts or it doesn't', and the very thing that is in question is what 'tallying' is here.” (1969, §199)

(4) Taken together, hinges form our "picture of the world" (Weltbild). (1969, §§93-94) Yet, it is not because we are, or have "satisfied ourselves of its correctness" that we hold on to it $(1969, \S 94)$; rather, this picture of the world is a "background" $(1969, \S 94)$ we have inherited and against which we distinguish between true and false. Hinges thus form a "substratum" (Substrat) for all our enquiries and assertions $(1969, \S 162)$. And "the propositions describing [our picture of the world] are not all equally subject to testing." $(1969, \S 162)$

(5) "It is the truth only inasmuch as it is an unmoving foundation of [the] language-games." $(1969, \S 403)$

(6) Their truth is kept fixed by what rotates around them $(1969, \S 152)$, like our methods of empirical investigation $(1969, \S 151, \S 318)$, and "the rest of our procedure of asserting." $(1969, \S 153)$

Thus, as a methodological point, when we are dealing with hinges, we have to focus on their role, rather than on their content (and possibly on the context of their use). As is apparent, they make it possible for us to engage in our empirical inquiries and investigations (1); for Wittgenstein, they also play a meaningconstitutive role, therefore they are conditions of possibility of meaningful discourse (2). Given their role, however, nothing can ultimately speak against them. For local doubts would have to presuppose them and global ones would be meaningless and not rational, for Wittgenstein. However, the fact that nothing can speak against them and that everything speaks in favour of them does not mean that they are unconditionally true - that is, that they are true because they correspond to a mind-independent reality that makes them true (3). Nor are they true because all of our evidence speaks in favour of them and therefore makes them true (3). For they make it possible for that evidence to be evidence in the first place. Thus, neither the correspondentist nor the evidence-dependent conception of truth applies to hinges. Rather, hinges determine the conditions of possibility for saying that a given proposition $p$ tallies with the facts, and is therefore true; as well as for saying that $p$ is true because all of our evidence speaks in favour of it. Moreover, in a Kantian flavour, being conditions of possibility for any kind of truth, let it be correspondentist or evidentialist, and of empirical rationality, for they make it possible to have evidence for or against ordinary empirical propositions, they do so because they are a parte subiecti $(4,5,6)$. Clearly there is also a flavour of historicism in Wittgenstein's thought, for, given his wide conception of hinges, he did think that at least some of them were subject to change at least over time $(1969, \S \S 96-99)$. Indeed, "nobody has ever been on the Moon" (cf. 1969, 106), which is a hinge for him, is no longer such for us. Moreover, in the passages on the riverbed metaphor, he concedes that the riverbed, that is our hinges, may change because of empirical discoveries and progress. Furthermore, there is also a flavour of relativism in On Certainty, as he sometimes 
envisions the possibility of communities that do not abide by our hinges and hold on to altogether different ones $(1969, \S 92, \S 132)$.

Now, the hinges I have been focusing on in my systematic work are more general and much more limited in number than Wittgenstein's. They are propositions like "There is an external world," "Our sense organs are broadly functioning correctly," or "Our cognitive faculties are broadly reliable." Still, they certainly are conditions of possibility of any empirical inquiry, whether or not they can also play a meaning-constitutive role. Moreover, they are presupposed by any ordinary empirical doubt, while also making it possible for any empirical evidence to play that very role. We can thus apply to them the idea that although nothing can speak against them and everything speaks in favour of them, that does not mean that they are unconditionally true. Nor are they true because they correspond to a mind-independent reality that makes them true. For it is only by accepting a hinge like "There is an external world" that we do have at least one of the terms in the equation for starting thinking that representations may or may not correspond, or tally with a mindindependent reality. The other term, in a Kantian flavour, can be entered in the equation only by holding on to the idea that there are minds, whose faculties - perceptual and cognitive - are broadly conducive to finding out about such a mind-independent reality. Indeed, this is what the other hinges I have been discussing in my more systematic work would give us. If so, this kind of hinges would be not just a condition of possibility of epistemic rationality, as I have maintained in previous work, but also a condition of possibility of there being representations at all — let them be linguistic, mental, pictorial, et cetera. Yet, it is equally mistaken to think that these general hinges are true because all of our evidence speaks in favor of them and therefore makes them true. For they are the conditions of possibility for that evidence to be evidence at all. As we saw, we need to take for granted that there are physical objects to let our sensory evidence speak in favour of, for example, "Here is a hand." Thus, neither the correspondentist nor the evidence-dependent conception of truth would apply to them. Rather, hinges would be the conditions of possibility for both saying that " $p$ tallies with the facts, and is therefore true"; as well as for saying that " $p$ is true because all of our evidence speaks in favor of it."

That being said, in a pluralistic spirit, we may might want to recognise the need for both kinds of truth, depending on the area of discourse at hand. I will allow myself to speak loosely of different kinds of truth. Really, however, what that means, in a developed pluralistic framework, is just that truth is differently realized (or determined) according to the kind of discourse at hand. More specifically, there would be a truthpredicate - "true" -, a truth-concept - TRUE -, a generic truth-property - truth-as-such - and its multiple realizations (e.g. truth as correspondence, or as superassertibility, or as coherence, etc.). That is to say, when we talk about Mount Everest and its height, we may have good reasons to think that whatever we think or say about that is true iff Mount Everest has such-and-such a property and it is because that is the case that what we think or say is true. Whereas, when we think or talk about a joke being funny, ultimately what we think or say is true iff the joke is funny, where the kind of truth predicated of "This joke is funny" is one that makes non-eliminable reference to human reactions. Thus, it is because we find that joke funny and are prepared to judge and assert that it is, that it is indeed funny. Now consider a ease sentence like "This sushi is tasty" and notice that it actually rests on "This is sushi" and "This is tasty." On this pluralist approach, the first sentence would express a proposition whose truth is mind-independent, while the second will express a proposition whose truth is grounded in our reactions. Mixed cases like this one are widespread and their significance is that, in many cases, our truth-determining reactions concern items belonging to a mindindependent reality. Thus, even if one did not endorse an evidence-dependent conception of truth for propositions about specific physical objects, it is of the essence of those areas of discourse for which an evidence-dependent account of truth has been invoked by alethic pluralists - that is, comic and taste discourse, but also aesthetic and moral discourse - that the relevant human reactions that are deemed truthdetermining targeted physical objects (including people), to which we have access and about which we can form beliefs, based on the operations of our sensory and cognitive faculties. In that mediated sense, then, even for a pluralist of the kind I am envisaging, the truth of "There is an external world," et cetera, would have to be taken for granted. ${ }^{12}$

Now, at this point, we might quite naturally want to stop thinking of hinges as being true (or false) altogether. I think that is what Wittgenstein ultimately ended up doing. ${ }^{13}$ Yet, we need not have to do that, as long as we are hospitable to the idea that truth may be sensibly predicated of hinges such that they can figure in disquotational schemas; that they can be embedded in conditionals, and thus be semantically assessable, or be embedded in meaningful negations, at least in further conditional statements. Yet, such predication would 
not be metaphysically robust, clearly. For the reasons just rehearsed, it could neither be taken as an ascription of a correspondence between these hinges and a mind-independent reality that makes them true, nor could it be taken as expressing the idea that since all of our evidence speaks in favour of them, that very evidence makes them true. It is thus in connection with hinges that I find a minimalist account of truth eminently plausible. Now However, "minimalism" is a name used for two different positions in the literature on truth and objectivity. One is Horwich's (1998) minimalism, which is a form of the deflationary theory of truth, which is non-redundantist and propositionalist as opposed to sententialist. The other one is Wright's (1992) minimalism, according to which a truth-predicate has to satisfy a number of platitudes, like the ones just mentioned, while the truth-property it expresses may vary as a function of the area of discourse at hand. By "minimalism" I will refer to the - no doubt unusual — synthesis of these views. For, like Wright and unlike Horwich, I take minimalism to be compatible with alethic pluralism, while, contra Wright and in the vein of Horwich, I am proposing that in certain areas of discourse the kind of truth predicated is exhausted by the Tschema and the platitudes traditionally licensed by deflationism. Discourse about hinges would be such an area. Thus,

$\left(\mathrm{T}_{\text {EXT }}\right)$ The proposition expressed by "There is an external world" is true iff there is an external world together with platitudes about negation, conditionals (and possibly some more see Lynch 2009) would be all there is to predicating truth of that proposition. Borrowing Lynch's terminology, we may call hinges "plain truths". That is, propositions whose truth just consists in the satisfaction of the relevant platitudes and is not grounded in anything else. Thus, they are not true in virtue of their correspondence to a mind-independent reality, or in virtue of being supported by all available evidence.

The virtue of such an approach would be to maintain the very possibility of predicating truth for these kinds of problematic propositions, while eschewing the problems that beset any of its possible stronger understandings. It would also tally quite well with the underlying understanding of hinges as conditions of possibility for representation, rather than as representations of a mind-independent reality themselves. Truth, in their regard, would thus be a "logical," or "grammatical" predication, which would not carry any stronger ontological commitment per se. Rather, it would simply entail that discourse about mind-independent objects is possible and is actually admitted among the kinds of discourse we engage in. Once that discourse is in place, specific moves within it become possible. Thus, a correspondentist account of truth could still find purchase for specific empirical claims such as

$\left(\mathrm{T}_{\mathrm{EVE}}\right)$ The proposition expressed by "Mount Everest is more than 8,000 meters high" is true iff Mount Everest in more than 8,000 meters high.

should one feel so inclined. Of course, the resulting realism would be weaker than what traditional supporters of that view might have thought (or wished). For it would be a kind of "internal realism," dependent on a previous commitment to the legitimacy of an entire area of discourse, which could not itself be redeemed in a correspondentist fashion. ${ }^{14}$ Yet, so much seems to me to be entailed by the endorsement of a hinge epistemology of Wittgensteinian descent. And if one did feel a hint of discomfort, one should always remind oneself of the alternatives, which I take to be worse by the lights of a self-aware, rather than naïve realist perspective. Namely, either to embrace deflationism about truth all the way down, including $\left(\mathrm{T}_{\mathrm{EVE}}\right)$ and its kin; or else to embrace correspondentism all the way down, but with dim prospects of being able to respond to sceptical paradoxes.

Notice, however, that there would be no hint of historicism or even of relativism in the kind of minimalism about hinges I have been proposing. This is because the hinges I have been considering and for which I have been proposing a minimalist treatment are very general ones, and can legitimately be seen as conditions of possibility of representational discourse tout court. The same does not seem true of many of Wittgenstein's hinges like "Nobody has ever been on the moon," or "My name is AC," "I have never been to Australia," "Nobody can make it rain," "Nobody can bring the world into existence with their own birth," et cetera, which may be subject to historical, cultural, or even personal variations. To repeat, I have been concerned with those hinges that allow us to think and talk about a mind-independent reality, and with those that allow us to take ourselves to be capable of engaging with such a world through our senses and our cognitive faculties.

Another issue which needs to be addressed, albeit briefly, is whether there is anything optional in these hinges. That is, could we opt for different ones or even opt out of them altogether, without endorsing any 
different ones? Idealists or phenomenalists may be taken as opting for different ones, such that physical objects would then coincide with clusters of sense experiences, or the like. Now, to the extent that such a position is ultimately coherent, for these sensory impressions would have to be produced by the interaction between our senses, which are physical organs, and something out there, which would be mind-independent, it would actually deprive us of the very possibility of engaging in fully representational discourse and would ultimately deprive us of the very possibility of engaging in epistemic rationality. That is to say, they would deprive us of the very possibility of engaging in those practices by means of which we hold, revise or withdraw from beliefs about mind-independent objects on the basis of evidence bearing on the mindindependent truth of those beliefs. These views, if ultimately coherent at all, would, at best, confine ourselves within a realm of internally coherent er ineoherent beliefs, which would not allow us to consider the latter as reaching anything else outside of them. Equally, opting out of these very general hinges, without endorsing different ones, would ultimately result in the impossibility of engaging in representational discourse and in epistemic practices constitutive of epistemic rationality, with not even a prima facie substitute for them. Most likely, that would result in cognitive paralysis. Thus, to the extent that representational discourse and epistemic rationality are valuable to us, we do have a strongly pragmatic, and as a universal as that might sensibly be reason to hold on to these very general hinges that make all of that possible. ${ }^{15}$

One may then wonder in what sense, if any, minimalism about hinges, as presented here, would count as an anti-realist position. It would clearly count as such if by "realism" one meant the view traditionally associated with correspondentism about truth. For minimalism denies that hinges are true because they correspond to a mind-independent reality. Still, minimalism would not be anti-realism traditionally understood either. For minimalism denies that hinges are true because our evidence speaks in favor of them. Eventually, I think that minimalism would pair very well with a form of quietism about the ultimate metaphysical status of hinges, understood as being the very conditions of possibility of representational talk and of epistemic rationality.

Thus, when it comes to hinges, if one thought that one would already be "going round in a circle" (1969, $\S 191$ ), if one tried to understand hinges" truth along evidence-dependent lines, and if one thought that "the ... use of the expression 'true or false' has something misleading about it," for "it is ... like saying "it tallies with the facts or it doesn't," when "the very thing that is in question is what 'tallying' is here" (1969, §199), then one should realise that the moment has come to cease to engage in robustly metaphysical speculations. That is where the spade reaches the bedrock and it would be turned if we did not stop and acknowledged that this is simply what we do.

Finally, one might wonder in what sense, if any, turning minimalist with respect to hinges' truth and quietist about the existence of an external world would help one respond to sceptical paradoxes. The answer to that worry is this: by rejecting the supposed unbridgeable distance between mind and world on which both Cartesian and Humean scepticism trade (as we saw in Sect. 2). For, on the picture advocated here, we are well within our rights in holding on to the existence of an external world broadly manifested to us through our sensory organs. Yet, we are within our rights not because we have a proof of that, but because it is part and parcel of engaging in representational discourse and in epistemic rationality as we - and, crucially, sceptics - do, that we take for granted the existence of physical objects and that our sensory faculties reliably allow us to engage with it.

\section{References}

Burge, Tyler. 2010. Origins of Objectivity. Oxford: Oxford University Press.

Coliva, Annalisa. 2010. Moore and Wittgenstein: Scepticism, Certainty and Common Sense. Basingstoke: Palgrave Macmillan.

2012. Scetticismo. Dubbio, Paradosso, Conoscenza. Roma-Bari: Laterza.

. 2015. Extended Rationality: A Hinge Epistemology. Basingstoke: Palgrave Macmillan.

2017a. Précis of Extended Rationality: A Hinge Epistemology. International Journal for the Study 
of Skepticism 7 (4): 217-234.

2017b. Replies to Commentators. International Journal for the Study of Skepticism 7 (4): 281-295.

DeRose, Keith. 1995. Solving the Skeptical Problem. Philosophical Review 104 (1): 1-52.

Dretske, Fred. 1970. Epistemic Operators. Journal of Philosophy 67 (24): 1007-1023.

Edwards, Douglas. 2011. Simplifying Alethic Pluralism. Southern Journal of Philosophy 49 (1): 28-48.

Horwich, Paul. 1998. Truth. Oxford: Clarendon.

Lynch, Michael. 2004. Truth and Multiple Realizability. Australasian Journal of Philosophy 82 (3): 384408.

2009. Truth as One and Many. Oxford: Oxford University Press.

McDowell, John. 1982. Criteria, Defeasibility and Knowledge. Proceedings of the British Academy 68: 455479.

1995. Knowledge and the Internal. Philosophy and Phenomenological Research 55 (4): 877-893.

Moyal-Sharrock, Danièle. 2005. Understanding Wittgenstein’s On Certainty. Basingstoke: Palgrave Macmillan.

Nozick, Robert. 1981. Philosophical Explanations. Cambridge, MA: Harvard University Press.

Pedersen, Nikolaj J.L.L., and Michael Lynch. 2018. Truth Pluralism. In The Oxford Handbook of Truth, ed. Michael Glanzberg. Oxford: Oxford University Press.

AQ1

Pedersen, Nikolaj J.L.L., and Cory Wright, eds. 2013. Truth and Pluralism: Current Debates. Oxford: Oxford University Press.

Pritchard, Duncan. 2016. Epistemic Angst: Radical Scepticism and the Groundlessness of Our Believing. Princeton: Princeton University Press.

Pryor, James. 2004. What's Wrong with Moore's Argument? Philosophical Issues 14 (1): 349-378.

Pryor, Jim. 2000. The Sceptic and the Dogmatist. Nô̂s 34 (4): 517-549.

Quine, W.v.O. (1969) 2008. Epistemology Naturalized. In Epistemology: An Anthology, ed. Ernest Sosa and Jaegwon Kim, 292-300. Oxford: Blackwell.

Sherman, Brett, and Gilbert Harman. 2011. Knowledge and Assumptions. Philosophical Studies 156 (1): $131-140$.

White, Roger. 2006. Problems for Dogmatism. Philosophical Studies 131 (3): 525-557.

Wittgenstein, Ludwig. 1969. On Certainty. Oxford: Oxford University Press.

Wright, Crispin. 1985. Facts and Certainty. Proceedings of the British Academy 71: 429-472. 
2007. The Perils of Dogmatism. In Themes from G. E. Moore: New Essays in Epistemology, ed. Susanna Nuccetelli and Gary Seay, 25-48. Oxford: Oxford University Press.

Clearly, Wittgenstein objected to the very possibility of global Cartesian scepticism for reasons briefly alluded to in the main text. Against a wholesale scepticism of Humean descent, he did appeal to the idea that rational — that is, justified—doubts could only be local. If so, hinges would have to be taken for granted to be able to formulate them. For a discussion of Wittgenstein's various antisceptical strategies, see Coliva (2010, chap. 3).

2 For other general presuppositions of epistemic rationality, see Coliva (2015, chap. 5).

Moyal-Sharrock (2005) has defended the anti-propositionalist reading of Wittgenstein's hinges. For a critical discussion, see Coliva (2010, chap. 2, 5).

On the notion of acceptance, see Coliva (2015, 33-39).

The charge is due to DeRose (1995). For a response, see Sherman and Harman (2011) and Coliva (2015, 136-39).

See Coliva (2015, 2017a, b, chap. 4) for replies to possible criticism.

I prefer to use the label "minimalist," rather than "deflationary," for reasons which will become apparent in the following.

This is the well-known problem of the criterion.

A Moorean argument would have roughly the following form:

(I) Here is a hand.

(II) If there is a hand here, there is an external world.

(III) There is an external world.

Now, (I) would be justified on the basis of one's on-going sensory experience. Yet, for that experience to be justifiably brought to bear on a belief about the existence of a specific physical object like a hand, (III) should already be taken for granted. Hence, whatever perceptual justification one could have for (I) could not be transmitted to (III), since prior justification for (III) would be needed in order to justifiably take (III) for granted and therefore for having a justification for (I) in the first place (Wright 1985). In Coliva (2015, chap. 3), I have proposed a different notion of transmission failure, which would depend merely on taking (III) for granted-without the need to have a justification for it - for (I) to be justified on the basis of one's on-going experience. For present purposes, it is irrelevant which kind of transmission failure is taken to apply to a Moorean argument.

10

10 For a philosophically informed discussion of work in contemporary cognitive psychology, see Burge (2010).

11 I do not think that ultimately Wittgenstein was a relativist, but just an anti-realist. I have discussed this issue at length in Coliva (2010, 188-207).

12 For different treatments of mixed compounds and inferences, in the vein of alethic pluralism, see Lynch (2004), Edwards (2011) and Pedersen and Lynch (forthcoming).

13 I thus concur with Moyal-Sharrock's (2005) interpretation. Cf. Coliva (2010).

14 This would tally with Wittgenstein's own understanding of "There are physical objects" as licensing talk about such a category of entities and of "A is a physical object" as being merely "a piece of instruction, which we give only to someone who doesn't yet understand either what 'A' means, or what 'physical object' mean." (1969, 36, cf. 35-37)

15 It falls beyond the scope of this paper to argue for the stronger claim that we have more than simply a pragmatic reason. A line one might want to explore, in order to argue for that stronger claim, is that being inquirers and knowers is essential to our identity, if not nature. Thus, insofar as we want to maintain that identity, or even more strongly, in virtue of our own nature, we cannot but stick to these hinges. 